\title{
Fabrication and physical characteristics of new glasses from wastes of limestone and phosphorite rocks
}

\author{
YASSER B SADDEEK ${ }^{1, *}$, K A ALY ${ }^{1,3}$, RABIE S FARAG ${ }^{2}$, M A M UOSIF ${ }^{1}$ and K H S SHAABAN ${ }^{1}$ \\ ${ }^{1}$ Faculty of Science, Physics Department, Al-Azhar University, Assiut 71524, Egypt \\ ${ }^{2}$ Faculty of Science, Chemistry Department, Al-Azhar University, Nasr City, Cairo, Egypt \\ ${ }^{3}$ Physics Department, Faculty of Science and Arts, University of Jeddah, P.O. Box 80200, Jeddah, Saudi Arabia
}

MS received 15 October 2015; accepted 10 May 2016

\begin{abstract}
In this work, new glasses were synthesized from wastes of limestone and phosphate rocks besides commercial borax. The glasses were characterized by FTIR, DTA, ultrasonic techniques and UV spectroscopy. It was found that the concentration of both $\mathrm{CaO}$ and $\mathrm{P}_{2} \mathrm{O}_{5}$ increases and the concentrations of $\mathrm{B}_{2} \mathrm{O}_{3}$ and $\mathrm{Na}_{2} \mathrm{O}$ decrease as the content of phosphate rocks increases. Variation of the contents of the different oxides affects the concentration of the structural units constituting the glass, which was indicated by the behaviour of the fraction $\mathrm{N}_{4}$ of $\mathrm{BO}_{4}$ units in the borate matrix. The density and the refractive index of the glasses decrease as the $\mathrm{CaO}$ and $\mathrm{P}_{2} \mathrm{O}_{5}$ contents increase, which was attributed to the increase of $\left[\mathrm{BO}_{3}\right]$ structural units. On the other hand, the physical parameters such as the ultrasonic velocity, the elastic moduli, the optical bandgap and the optical polarizability increased, which was attributed to the higher coordination number of $\mathrm{CaO}_{6}$ compared with the coordination of borate structural units and to the former effect of $\mathrm{P}_{2} \mathrm{O}_{5}$. As a result, a polymerization of the total co-ordination number of the glass, crosslink density and connectivity within the glass network will occur.
\end{abstract}

Keywords. Recycling; calcium borate glasses; elastic moduli; FTIR.

\section{Introduction}

Large amounts of wastes are produced every year in the process of extraction of limestone and phosphorite from quarries of Egypt. These wastes affect badly the local environment by creating dust and noise. Also, phosphorite rocks represent a pollution source of some radioactive elements such as uranium and thorium [1,2]. The main component of the extracted limestone is crystals of calcium carbonate $\left(\mathrm{CaCO}_{3}\right)$, while the main source for phosphate is rocks containing concentrations of calcium phosphate mineral $[3,4]$. Limestone can be used as a soil conditioner to neutralize acidic soils, a solid base for many roads, in asphalt concrete [5]. Phosphates were used in fertilizers for agriculture, as animal feed supplements and in ceramics industry [4].

Recycling management of solid wastes is a very important topic both from the public health point of view and also the industrial affairs $[5,6]$. Cheap and abundant wastes of raw materials like limestone and phosphorite can be considered as starting materials for commercial glass industries. According to extensive research works, modification of the concentrations of the commercial glasses can be used in the vitrification of high-level radioactive wastes, in fuel cell applications, microelectronics industry and in some bioactive materials [7-9].

There have been many investigations on glass materials in the ternary $\mathrm{CaO}-\mathrm{B}_{2} \mathrm{O}_{3}-\mathrm{Na}_{2} \mathrm{O}$ glass system during previous

\footnotetext{
*Author for correspondence (ysaddeek@gmail.com)
}

years [10]. The investigations were focused on the structure of these glasses by using several techniques [11,12]. This type of glass can be considered as one of the compositions based on commercial glasses. Thus, in this work, preparation of transparent glasses with low melting temperature from wastes of limestone and phosphorite rocks with the aid of commercial borax was inspected. A complete characterization of the glasses was performed by FTIR, DTA, ultrasonic techniques and UV spectroscopy.

\section{Experimental}

The glasses in this study were synthesized from commercial borax and wastes from limestone and phosphorite using the melt-quench technique. The limestone was taken from ElMinia quarry_Egypt and phosphorite rocks were taken from El-Sibaiya mine-Egypt. The chemical compositions of the used materials were analysed using X-ray fluorescence technique and their values are listed in table 1 . In accordance with the nominal glass compositions presented in table 2 , homogeneous mixtures of batches $(75 \mathrm{~g})$ were melted at $1200^{\circ} \mathrm{C}$ for a time period of $1 \mathrm{~h}$ under normal atmospheric conditions, after which the glass was quenched by pouring into a preheated cubic stainless steel mold with dimensions $1 \mathrm{~cm}^{3}$ and was then slowly cooled to room temperature. To ensure the homogeneity of the glass, the well-mixed components were added in small portions and the melt was swirled frequently [13]. The glasses were annealed at $500^{\circ} \mathrm{C}$ for $2 \mathrm{~h}$ to 
relieve the internal stresses and allowed to cool gradually to room temperature at a rate of about $30^{\circ} \mathrm{C} \mathrm{h}^{-1}$. The weight losses were found to be less than $1 \%$. The prepared samples were grinded and polished with different grades of $\mathrm{SiC}$ emery powder on a soft leather piece fixed on a flat platform for the ultrasonic velocity measurements. Non-parallelism of the two opposite side faces was measured with a micrometer, which could measure down to $0.01 \mathrm{~mm}$.

The amorphous state of the glasses was checked using $\mathrm{X}$-ray diffraction. A Philips X-ray diffractometer PW/1710 with $\mathrm{Ni}$-filtered $\mathrm{Cu}-\mathrm{K} \alpha$ radiation $(\lambda=1.542 \AA)$ powered at $40 \mathrm{kV}$ and $30 \mathrm{~mA}$ was used. The patterns as shown in figure 1 revealed the characteristic broad humps of the amorphous materials and did not reveal discrete or any sharp peaks. The density of each sample was measured by Archimedes' principle by using toluene as the immersion fluid. Four samples of each glass were used to determine the density $(d)$. A random error in the density values was found as $\pm 25 \mathrm{~kg} \mathrm{~m}^{-3}$.

FTIR spectra of the as-quenched glasses (after crushing them into powder form) were obtained with a Fourier transform IR spectrometer (JASCO, FT/IR-430, Japan). For this purpose, each glass powder was mixed with $\mathrm{KBr}$ in the proportion of 1:100 (by weight) for $20 \mathrm{~min}$ and pressed into a pellet using a hand press. At least two spectra for each sample were recorded in the wavenumber range of $1700-400 \mathrm{~cm}^{-1}$ with a resolution of $4 \mathrm{~cm}^{-1}$, corrected for dark-current noise and normalized. The resulting spectra were curve fitted to get quantitative values for the band areas of heavily overlapped bands using a computer program Origin 8. Estimated error limit in the fitting process is about $\pm 2 \mathrm{~cm}^{-1}$.

The pulse-echo method enabled the measuring of the ultrasonic velocities, longitudinal $\left(v_{\mathrm{L}}\right)$ and transverse $\left(v_{\mathrm{T}}\right)$, at room temperature $(\sim 300 \mathrm{~K})$ using $x$-cut and $y$-cut transducers (KARL DEUTSCH) operated at a fundamental frequency $4 \mathrm{MHz}$ along with a digital ultrasonic flaw detector (KARL DEUTSCH Echo graph model 1085). The uncertainty in the measurement of the ultrasonic velocity is $\pm 10 \mathrm{~m} \mathrm{~s}^{-1}$. The independent second-order elastic constants for isotropic solids and glasses, $L$ and $G$, can be determined as $L=\rho v_{\mathrm{L}}^{2}$, and $G=\rho v_{\mathrm{T}}^{2}$ and can be used in computing the elastic bulk modulus $(K)$ and Young's modulus $(Y)$ [14]. The uncertainty in the measurement of the elastic moduli is $\pm 0.15 \mathrm{GPa}$.

Optical transmittance spectra have been measured at room temperature using a double beam (Jasco-V670) computercontrolled spectrophotometer, at normal incidence of light and in the wavelength range 500-2500 $\mathrm{nm}$.

Table 1. The chemical composition of the constituents of the parent limestone, phosphate rock and commercial borax (wt\%).

\begin{tabular}{lccc}
\hline Oxides & Limestone & Phosphate rock & Commercial borax \\
\hline $\mathrm{CaO}$ & 97.81 & 76.62 & 6.8 \\
$\mathrm{SiO}_{2}$ & 0 & 4.21 & 4.3 \\
$\mathrm{~B}_{2} \mathrm{O}_{3}$ & 0 & 0 & 57.2 \\
$\mathrm{Na}_{2} \mathrm{O}$ & 0 & 0 & 28.6 \\
$\mathrm{P}_{2} \mathrm{O}_{5}$ & 0 & 12.88 & 0 \\
$\mathrm{Fe}_{2} \mathrm{O}_{3}$ & 0.079 & 1.91 & 0 \\
$\mathrm{SrO}_{\mathrm{O}}$ & 0.078 & 0.32 & 0.3 \\
$\mathrm{Co} \mathrm{O}_{4}$ & 0.059 & 0 & 0 \\
$\mathrm{CuO}$ & 0.067 & 0 & 0 \\
$\mathrm{SO}_{3}$ & 0 & 1.35 & 0 \\
$\mathrm{CdO}$ & 0 & 0.93 & 0 \\
$\mathrm{RuO}_{2}$ & 0.65 & 0 & 0 \\
$\mathrm{Er}_{2} \mathrm{O}_{3}$ & 0.09 & 0 & 0 \\
$\mathrm{Lu}_{2} \mathrm{O}_{3}$ & 0.1 & 0 & 0 \\
$\mathrm{BaO}$ & 0 & 0 & 1.3 \\
\hline
\end{tabular}

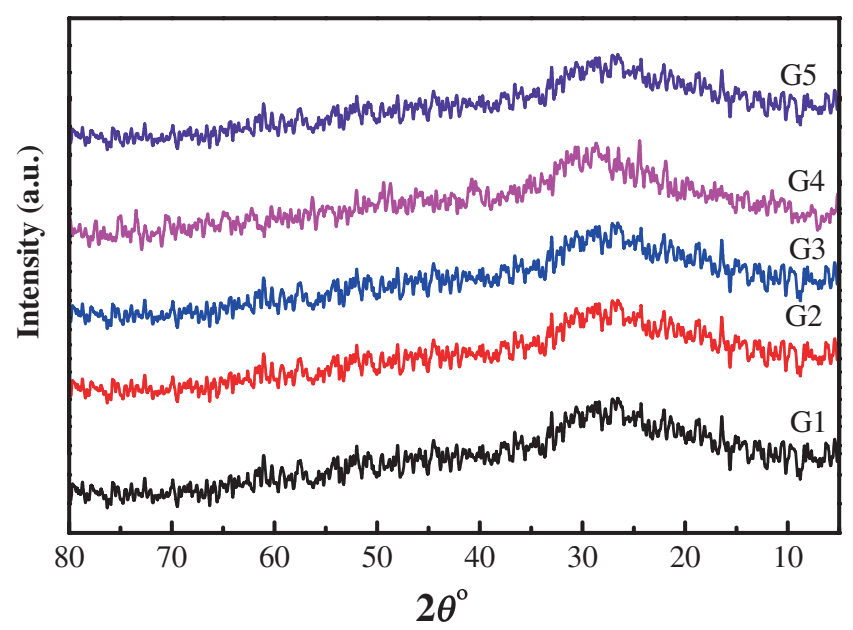

Figure 1. XRD spectra of the investigated $x$ (phosphate rocks) 30 (limestone) $-(70-x)$ borax $(0 \leq x \leq 40 \mathrm{wt} \%)$ glasses.

Table 2. The glass compositions and different oxides of $x$ (phosphate rocks) -30 (limestone) $-(70-x)$ borax $(0 \leq x \leq$ $40 \mathrm{wt} \%$ ) glass system.

\begin{tabular}{|c|c|c|c|c|c|c|c|c|c|c|}
\hline \multirow[b]{2}{*}{ Sample number } & \multicolumn{3}{|c|}{ Chemical composition (wt $\%$ ) } & \multicolumn{7}{|c|}{ Chemical composition (mol\%) } \\
\hline & Borax & Limestone & Phosphate rock & $\mathrm{CaO}$ & $\mathrm{B}_{2} \mathrm{O}_{3}$ & $\mathrm{Na}_{2} \mathrm{O}$ & $\mathrm{SiO}_{2}$ & $\mathrm{P}_{2} \mathrm{O}_{5}$ & $\mathrm{Fe}_{2} \mathrm{O}_{3}$ & $\mathrm{SrO}$ \\
\hline G1 & 70 & 30 & 0 & 40 & 36 & 20 & 3.6 & 0 & 0.2 & 0.2 \\
\hline $\mathrm{G} 2$ & 60 & 30 & 10 & 47 & 31 & 17 & 3.6 & 1.1 & 0.2 & 0.1 \\
\hline G3 & 50 & 30 & 20 & 55 & 26 & 14 & 3.5 & 1.2 & 0.2 & 0.1 \\
\hline G4 & 40 & 30 & 30 & 62 & 20 & 12 & 3.5 & 2.2 & 0.2 & 0.1 \\
\hline G5 & 30 & 30 & 40 & 70 & 15 & 9 & 3.3 & 2.4 & 0.2 & 0.1 \\
\hline
\end{tabular}




\section{Results and discussion}

\subsection{Infrared spectral studies}

Comprehensive insights of the analysis of FTIR spectra of the studied glasses can be correlated to the analysis of the oxides incorporated in the resulting glass compositions [15]. The analysis revealed that increasing the content of phosphorite rocks in the glass batch will increase the concentrations of $\mathrm{CaO}$ and $\mathrm{P}_{2} \mathrm{O}_{5}$ and decrease the sodium diborate ratio while the concentration of $\mathrm{SiO}_{2}$ will be constant. Table 2 presents the concentration of each oxide in the investigated glass compositions.

The room-temperature FTIR absorption spectra of all the investigated glasses are shown in figure 2. The FTIR spectra of all the investigated glasses exhibit four broad absorption bands for sample G1 and five broad absorption bands for the other samples in the region of $400-1600 \mathrm{~cm}^{-1}$. Manifestation of the broad band indicated the wide distribution of the structural units occurring in these glasses [16]. The most intense bands of the base glass lie in the $775-1150 \mathrm{~cm}^{-1}$ region and the moderate intensive bands lie between 1300 and $1600 \mathrm{~cm}^{-1}$, while the least intensive bands lie between $1150-1300 \mathrm{~cm}^{-1}$ and $630-775 \mathrm{~cm}^{-1}$. There are two small bands at 475 and $555 \mathrm{~cm}^{-1}$. The bands in the region 775$1150 \mathrm{~cm}^{-1}$ were attributed to $\mathrm{B}-\mathrm{O}$ vibrations in the $\left[\mathrm{BO}_{4}\right]$ tetrahedral [17], the bands in the region 1150-1600 $\mathrm{cm}^{-1}$ may be related to vibrations of $\mathrm{B}-\mathrm{O}$ in the $\left[\mathrm{BO}_{3}\right]$ triangle [18] and the bands at $\sim 630-775 \mathrm{~cm}^{-1}$ were attributed to bending vibrations of bridging oxygen between trigonal boron atoms [19]. The two small bands at 475 and $555 \mathrm{~cm}^{-1}$ may be attributed to the vibrations of some type of borate segments and to the bending vibrations of $\mathrm{Si}-\mathrm{O}-\mathrm{Si}$ linkages [20].

The broad FTIR band of the glass was attributed to the overlapping of some individual bands with each other. Each individual band has its centre $(C)$, which is related to the vibrations of a specific structural group, and its relative area

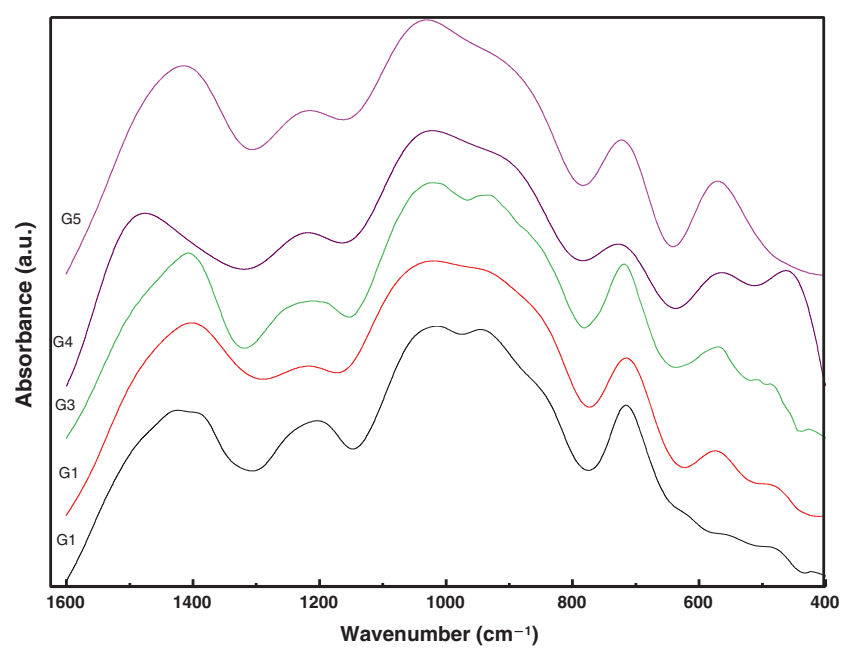

Figure 2. FTIR spectra of the investigated $x$ (phosphate rocks) 30 (limestone) $-(70-x)$ borax $(0 \leq x \leq 40 \mathrm{wt} \%)$ glasses.
(A), which is proportional to the concentration of this structural group. A deconvolution process has to be performed to obtain such parameters [14]. The deconvolution parameters of the bands for the investigated glasses along with their assignments of the vibration modes are given in table 3 . The values of these parameters agreed well with those reported by Saddeek et al [1,2] and Ren et al [13]. As a comparative example, figure 3 shows the deconvoluted spectrum of the glass sample G3. The fraction $\left(N_{4}\right)$ of four-coordinated boron atoms can be calculated by considering the assignment of the different bands (table 3) and the area under the component bands [21].

It was reported that the formation of $\mathrm{BO}_{3}, \mathrm{BO}_{4}$ and $\mathrm{BO}_{4}^{-}$ borate structural units is sensitive for the ratio of the concentrations of alkaline earth oxide such as $\mathrm{CaO}$ to the content of sodium diborate. Hence, pronounced effect of $\mathrm{CaO}$ on the FTIR bands of the network of the glass samples was observed in the range $40 \leq \mathrm{CaO} \leq 55 \mathrm{~mol} \%$. In this range, as the $\mathrm{CaO}$ concentration increased, the concentration of the $\mathrm{CaO}_{6}$ structural unit increased, which transformed the $\mathrm{BO}_{4}$ tetrahedron into $\mathrm{BO}_{3}$ structural unit. This transformation was indicated by the decrease in the relative area of $\left[\mathrm{BO}_{4}\right]$, and the $N_{4}$ while the relative area of $\mathrm{BO}_{3}$ structural units increases, i.e., there is a depolymerization in the glass network [10]. Beyond $55 \mathrm{~mol} \%$ of $\mathrm{CaO}$, the effect of the network glass former $\mathrm{P}_{2} \mathrm{O}_{5}$ was manifested in the appearance of new structural units such as $\left[\mathrm{PO}_{2}^{-}\right]$, which was bonded together by oxygen vertices as indicated from the overlapped bands at around $\sim 475 \mathrm{~cm}^{-1}$ [22]. The new $\left[\mathrm{PO}_{2}^{-}\right]$structural units shift the vibrations of $\left[\mathrm{BO}_{3}\right]$ to lower wavenumbers and the vibrations of $\left[\mathrm{BO}_{4}\right]$ to higher wavenumbers. The presence of glass network-forming cations ( $\mathrm{P}$ in the present case) in the glass promotes the formation of new covalent bonds of calcium phosphate network. In a calcium phosphate glass system, $\mathrm{P}_{2} \mathrm{O}_{5}$ acts as a network former even at low concentrations while alkaline-earth cations were located near $\left[\mathrm{PO}_{2}^{-}\right]$and balanced their negative charges. Accordingly, the transformation of $\left[\mathrm{BO}_{4}\right]$ into $\left[\mathrm{BO}_{3}\right]$ structural units will be very slow and the fraction $N_{4}$ will no longer be affected with the variations in the glass composition. Also, in this range, there is an increase in the abundance of bridging oxygens and consequentially, results in a re-polymerization of the glass network as suggested before [22]. The bridging oxygens help in creating new $\mathrm{P}-$ $\mathrm{O}-\mathrm{Ca}, \mathrm{P}-\mathrm{O}-\mathrm{Na}$ and $\mathrm{P}-\mathrm{O}-\mathrm{P}$ bonds. These bonds are expected because both $\mathrm{P}$ and $\mathrm{B}$ atoms have comparable electronegativity and can therefore substitute for each other in bonding with $\mathrm{O}$ atoms [23]. Accordingly, it can be suggested that the average force constant of the glass network will increase with increasing $\mathrm{CaO}$ content in this region. The computation of the average force constant was reported elsewhere [24]. This increase can be attributed to the higher bond strength of $\mathrm{CaO}_{6}$ and $\mathrm{PO}_{2}^{-}$relative to that of $\mathrm{BO}_{3}$, and to the higher coordination number (4) of $\mathrm{CaO}$ compared with that of $\mathrm{B}_{2} \mathrm{O}_{3}$ (3 or 4 ), which increases the number of bonds per unit volume [25]. Thus, the presence of structural units of a glass former such as $\mathrm{P}_{2} \mathrm{O}_{5}$ modifies the structure of the glass network by improving the glass stability, the chemical durability 
Table 3. The curve-fitting parameters (the band centres $C$ and the relative area $A \%$ ) for the glasses along with the assignments of the bands.

\begin{tabular}{|c|c|c|c|c|c|c|c|c|c|c|}
\hline \multicolumn{2}{|c|}{ G1 } & \multicolumn{2}{|c|}{ G2 } & \multicolumn{2}{|c|}{ G3 } & \multicolumn{2}{|c|}{ G4 } & \multicolumn{2}{|c|}{ G5 } & \multirow[b]{2}{*}{ Assignment } \\
\hline $\boldsymbol{A}$ & $C$ & $A$ & $C$ & $A$ & $C$ & $A$ & $C$ & $A$ & $C$ & \\
\hline - & - & - & - & 2.79 & 429 & 2.63 & 452 & 3.83 & 444 & Bending vibrations of $\mathrm{PO}_{2}^{-}$groups \\
\hline - & - & 1.51 & 509 & 3.27 & 507 & 3.37 & 511 & 4.3 & 475 & \\
\hline 1.78 & 547 & 2.95 & 585 & 5.16 & 573 & 5.56 & 598 & 5.17 & 590 & $\mathrm{Si}-\mathrm{O}$ in the silicon-oxygen framework of the glass \\
\hline 3.86 & 649 & 5.17 & 693 & 3.77 & 708 & 5.33 & 663 & 5.07 & 689 & Bending vibration of $\mathrm{B}-\mathrm{O}-\mathrm{B}$ in $\mathrm{BO}_{3}$ triangles \\
\hline 5.27 & 717 & 6.15 & 783 & 4.55 & 751 & - & - & 5.81 & 736 & \\
\hline 6.65 & 801 & - & - & - & - & - & - & - & - & \\
\hline- & - & - & - & - & - & 9.32 & 827 & 6.87 & 840 & \\
\hline 8.49 & 866 & 9.13 & 885 & 5.8 & 867 & 9.22 & 899 & 9.46 & 900 & \\
\hline 10.9 & 954 & 11 & 975 & 8 & 928 & 10.3 & 968 & 10.2 & 983 & Stretching vibrations of $\mathrm{BO}_{4}$ units in \\
\hline 9.9 & 1000 & - & - & - & - & - & - & - & - & various structural groups \\
\hline 10.1 & 1079 & 11.4 & 1050 & 10.7 & 1002 & 10.3 & 1044 & 10.2 & 1059 & \\
\hline- & - & 10.5 & 1099 & 10.7 & 1075 & - & - & 7.88 & 1115 & \\
\hline 8.82 & 11314 & - & - & 10.1 & 1181 & 8.39 & 1174 & & & \\
\hline - & - & - & - & - & - & - & - & 7.95 & 1208 & \\
\hline - & - & 10.1 & 1212 & 8.14 & 1246 & 8.65 & 1239 & 7.55 & 1267 & Stretching vibrations of $\mathrm{BO}_{3}$ units with \\
\hline 8.14 & 1297 & - & - & - & - & - & - & - & - & and without nonbridging oxygen ions \\
\hline 10.2 & 1346 & 10.2 & 1346 & 7.55 & 1350 & 7.94 & 1354 & 7.73 & 1380 & \\
\hline 9.47 & 1438 & 11.6 & 1430 & 12.1 & 1408 & 9.64 & 1438 & 7.98 & 1492 & \\
\hline 6.44 & 1535 & 10.2 & 1510 & 7.42 & 1495 & 9.35 & 1527 & - & - & \\
\hline
\end{tabular}

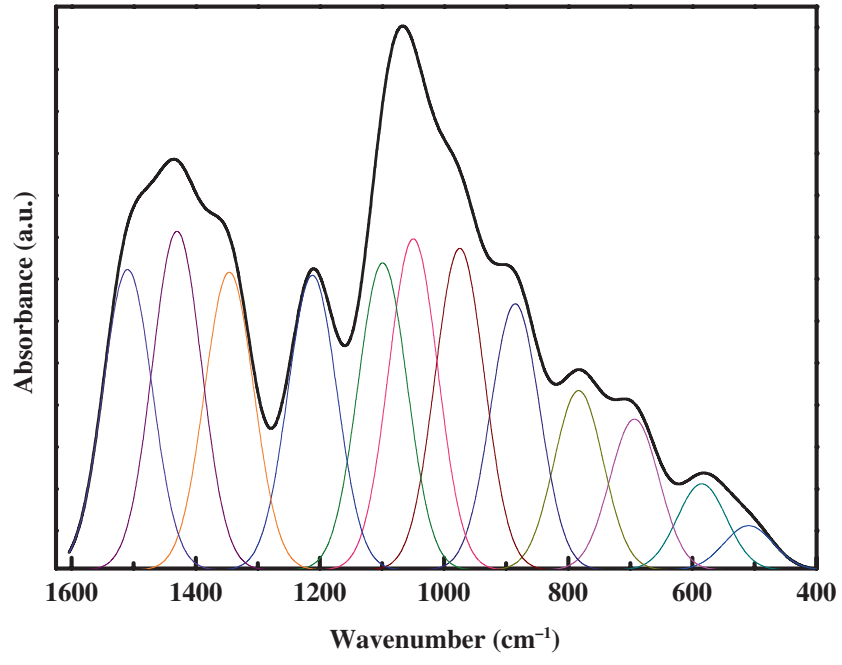

Figure 3. Curve fitting of FTIR spectra of the glass 20(phosphate rocks) - 30(limestone) -50 borax.

and hence increasing the number of bridging oxygens, coordination number, crosslink density and connectivity within the glass network.

\subsection{Elastic properties studies}

The density of borate-based glasses is an intrinsic property capable of casting light on the conversion of its basic structural unit $\mathrm{BO}_{3}$ into four-fold $\mathrm{BO}_{4}$-coordinated boron atoms and vice versa $[13,26]$. The compositional dependence of the density $(d)$ on the $\mathrm{CaO}$ content of the investigated glasses is

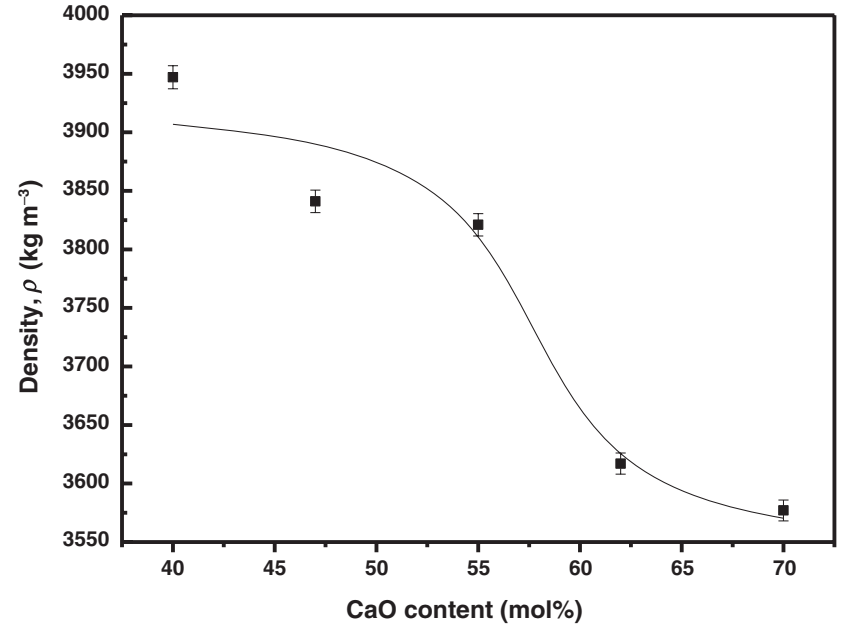

Figure 4. Dependence of the density in $x$ (phosphate rocks) - 30(limestone) $-(70-x)$ borax $(0 \leq x \leq 40 \mathrm{wt} \%)$ glasses on the $\mathrm{CaO}$ content. The uncertainty in the measurement is $\pm 25 \mathrm{~kg} \mathrm{~m}^{-3}$.

shown in figure 4 and their values are listed in table 4 . As shown in figure 3 , the density of the studied glasses decreases as the $\mathrm{CaO}$ content increases and their values are near those of other researchers $[27,28]$. The decrease process can be attributed to the transformation of $\left[\mathrm{BO}_{4}\right]$ into $\left[\mathrm{BO}_{3}\right]$ structural units. It was reported that the $\left[\mathrm{BO}_{4}\right]$ is denser than $\left[\mathrm{BO}_{3}\right]$ or $\left[\mathrm{PO}_{2}^{-}\right]$structural units and is responsible for the increase in the binding of the glass network and the degree of the structural compactness [13,27]. A sudden change in the rate of decreasing the density at a ratio of $55 \mathrm{~mol} \%$ of $\mathrm{CaO}$ content was found, which may be attributed to the manifestation of $\left[\mathrm{PO}_{2}^{-}\right]$structural unit and the intense reduction of the 
Table 4. The density, ultrasonic velocities $\left(v_{\mathrm{L}}\right.$ and $\left.v_{\mathrm{T}}\right)$ and the elastic moduli (longitudinal $\left(C_{11}\right)$, shear $\left(C_{44}\right)$, Young's modulus $(E)$ and bulk modulus $(K))$ of $x$ (phosphate rocks) - 30(limestone) $-(70-x)$ borax $(0 \leq x \leq 40 \mathrm{wt} \%)$ glass system.

\begin{tabular}{|c|c|c|c|c|c|c|c|c|}
\hline \multirow[b]{2}{*}{ Sample } & \multirow[b]{2}{*}{$d\left(\mathrm{~kg} \mathrm{~cm}^{-3}\right)$} & \multirow[b]{2}{*}{$v_{\mathrm{L}}\left(\mathrm{m} \mathrm{s}^{-1}\right)$} & \multirow[b]{2}{*}{$v_{\mathrm{T}}\left(\mathrm{m} \mathrm{s}^{-1}\right)$} & $C_{11}$ & $C_{44}$ & $K$ & $Y$ & \multirow[b]{2}{*}{$N_{4}$} \\
\hline & & & & \multicolumn{4}{|c|}{$(\mathrm{GPa})$} & \\
\hline G1 & 3947 & 6251 & 3648 & 154.2 & 52.5 & 84.2 & 130.4 & 0.56 \\
\hline G2 & 3841 & 6381 & 3698 & 156.4 & 52.5 & 86.4 & 131.0 & 0.46 \\
\hline G3 & 3821 & 6425 & 3717 & 157.75 & 52.8 & 87.4 & 131.8 & 0.51 \\
\hline G4 & 3617 & 6623 & 3818 & 158.6 & 52.7 & 88.4 & 131.9 & 0.53 \\
\hline G5 & 3577 & 6719 & 3841 & 161.5 & 52.8 & 91.1 & 132.7 & 0.53 \\
\hline
\end{tabular}

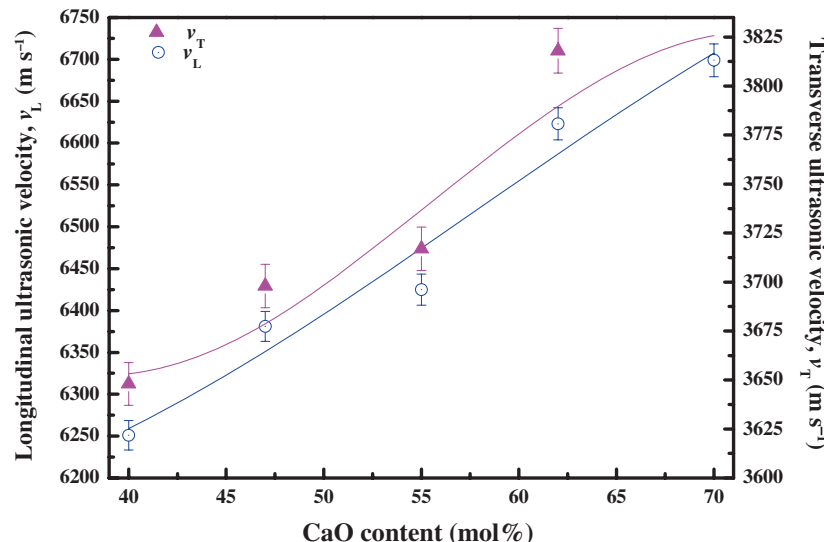

Figure 5. Dependence of the longitudinal and shear ultrasonic velocities $v_{\mathrm{L}}$ and $v_{\mathrm{T}}$ in $x$ (phosphate rocks) - 30(limestone) - (70$x)$ borax $(0 \leq x \leq 40 \mathrm{wt} \%)$ glasses on the $\mathrm{CaO}$ content. The uncertainty in the measurement is $\pm 15 \mathrm{~m} \mathrm{~s}^{-1}$.

conversion of $\left[\mathrm{BO}_{4}\right]$ into $\left[\mathrm{BO}_{3}\right]$. It seemed that the type of the formed structural units controlled the decrease of the density rather than the masses of the constituents. The behaviour of the density is in a good agreement with the FTIR analysis and the rate of decrease of the density can be correlated to the variation of $N_{4}$.

On the other hand, the longitudinal $\left(v_{\mathrm{L}}\right)$ and shear ultrasonic $\left(v_{\mathrm{T}}\right)$ velocities of the glass system with different mol\% of $\mathrm{CaO}$ content are depicted in figure 5. It was found that, both velocities $\left(v_{\mathrm{L}}\right)$ and $\left(v_{\mathrm{T}}\right)$ were increased as the $\mathrm{CaO}$ content increased and the values of $\left(v_{\mathrm{L}}\right)$ are higher than those of $\left(v_{\mathrm{T}}\right)$ [27]. The increase in the ultrasonic velocity of the studied glasses can be explained by taking the following factors into consideration.

(i) As the concentration of the phosphate rocks increases, the network glass modifier $\mathrm{CaO}$ and the glass former $\mathrm{P}_{2} \mathrm{O}_{5}$ increase while the sodium diborate content decreases. Hence, as discussed previously, $\mathrm{CaO}$ modifies the amorphous network by increasing the concentration of the structural unit $\mathrm{CaO}_{6}$, which had high coordination number compared with the coordination of borate structural units. As a result, a polymerization of the total co-ordination number of the glass, crosslink density and connectivity within the glass network will occur.

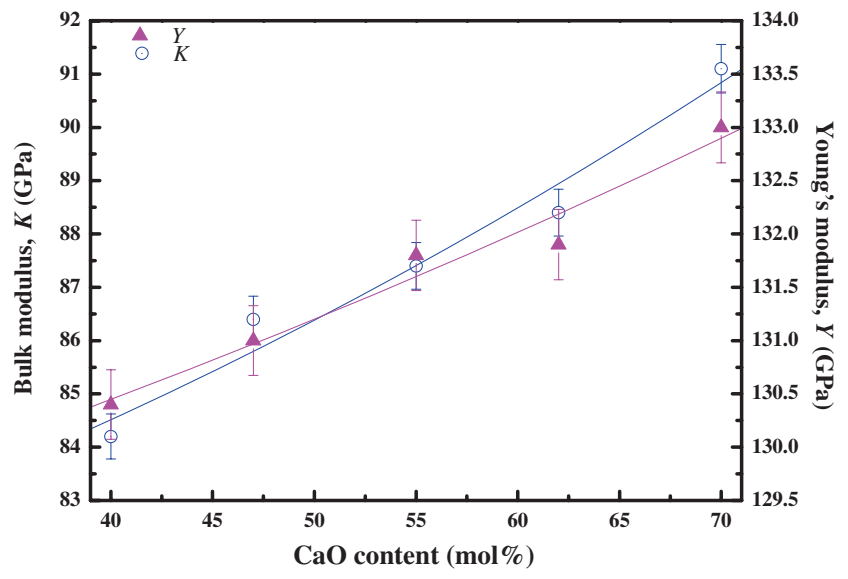

Figure 6. Composition dependence of the Young's modulus $(E)$ and bulk modulus $(K)$ on the $\mathrm{CaO}$ content of $x$ (phosphate rocks) 30 (limestone) $-(70-x)$ borax $(0 \leq x \leq 40 \mathrm{wt} \%)$ glasses. The error limit is estimated as $\pm 0.15 \%$.

(ii) The packing density of $\mathrm{CaO}_{6}, \mathrm{BO}_{3}, \mathrm{BO}_{4}$ and $\left[\mathrm{PO}_{2}^{-}\right]$ can be given as 9.4, 15.2, $20.8 \times 10^{-6}$ and $34.8 \times$ $10^{-6} \mathrm{~m}^{3} \mathrm{~mol}^{-1}$, respectively $[1,2]$. Thus, it can be concluded that $\mathrm{CaO}$ plays a dominant role in borate-based glasses by making the glass harder, compacted and rigid, which increase the ultrasonic velocities.

On the other hand, Young's modulus is related to the bond strength of the materials, while the bulk modulus $(K)$ was defined as the change in volume when a force is acted upon it in all directions [29]. In this work, the elastic moduli behave in a manner similar to that observed for ultrasonic wave velocities as shown in figure 6 . The attainment of a higher value of $Y$ than $K$ indicated that the glasses were able to resist a higher longitudinal stress than transverse stress. The increase in $K$ with an increasing in the $\mathrm{CaO}$ content was due to the change in the coordination number and the higher bond strength of $\mathrm{CaO}_{6}$ than that of $\mathrm{BO}_{3}$ structural units, i.e., it depends on the type of the bonds between atoms in the network. Since the addition of $\mathrm{CaO}$ increases the rigidity of glass structure $[21,25]$, the velocity and elastic moduli would also increase.

On the other hand, the variations of the elastic moduli can control the dimensionality and consequently the Poisson's ratio of amorphous network. As reported elsewhere, the dimensionality of a glass matrix can be related to the elastic 
moduli by the relation $4 C_{44} / K$. This ratio for the studied glasses is about 2.4 , i.e., the structure is three-dimensional with increasing cross-links. Also, $C_{44} / C_{12}, C_{12}=C_{11}-2 C_{44}$ can describe the character of the force field which is about 1 in these glasses, i.e., a central force between structural units may be established.

\subsection{Optical properties}

Figure 7 depicts the measured transmittance and reflectance ( $T$ and $R$ ) spectra for the studied glass samples. It is found that optical absorption edge is not sharply defined in the present glasses, which clearly indicates their glassy nature. As illustrated in this figure, the addition of $\mathrm{CaO}$ shifts the optical spectra to the low-wavelength side (i.e., to the blueshift of the optical band gap) [30,31]. Based on the measured $T$ and $R$ values, the absorption coefficient was calculated in Ref. [32] as follows:

$$
\alpha(\lambda)=\frac{1}{x} \ln \left(\frac{1-R}{T}\right),
$$

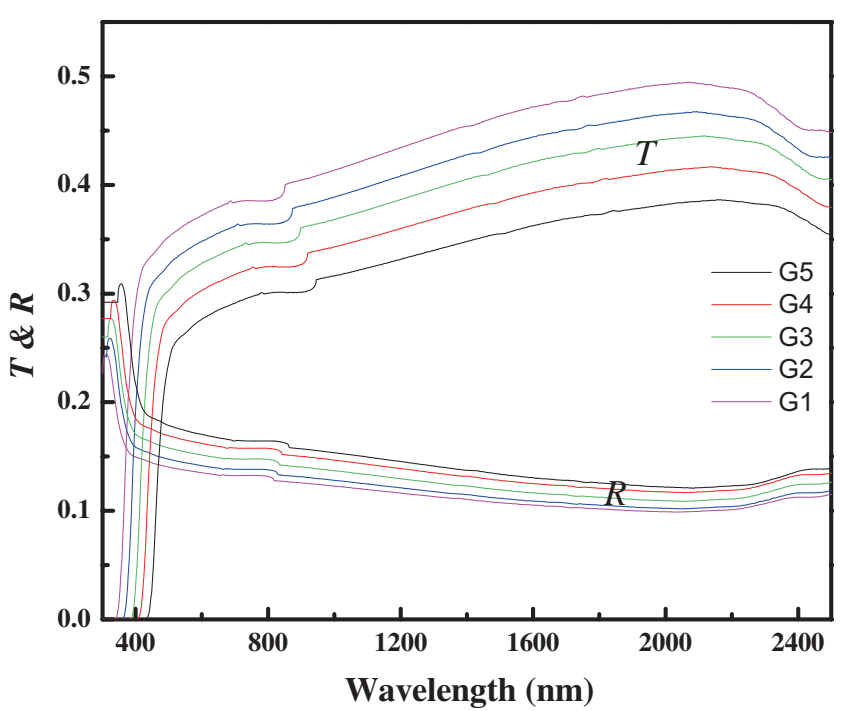

Figure 7. The measured transmittance $T(\lambda)$ and reflectance $R(\lambda)$ spectra for G1-G5 glasses. where $x$ is sample thickness. In the high-absorption region, the photon energy dependence of the absorption coefficient obeys Tauc's formula [33]:

$$
\alpha h v=B\left(h v-E_{\mathrm{g}}\right)^{p},
$$

where $E_{\mathrm{g}}$ is the optical bandgap, $B$ an energy-independent constant and the exponent $p$ takes different values depending on the mechanism of inter-band transitions $(p=1 / 2$ for direct and $p=2$ for non-direct transitions) [32]. The linear relation of the absorption coefficient parameter $\sqrt{\alpha h v} v s$. $h v$ for G1-G5 glasses is presented in figure 8. As seen in this figure, the transitions in the forbidden gap are indirect, i.e., $p=1 / 2$. The intercept of $\sqrt{\alpha h v} v s$. $h v$ at $\sqrt{\alpha h v}=0$ denotes the value of $E_{\mathrm{g}}$. The values of $E_{\mathrm{g}}$ as listed in table 5 increase with the increase of $\mathrm{CaO}$ content. On the other side, the energy dependence of the absorption coefficient in the region of low absorption can be expressed as [30]

$$
\alpha=\alpha_{0} e^{h v / \gamma},
$$

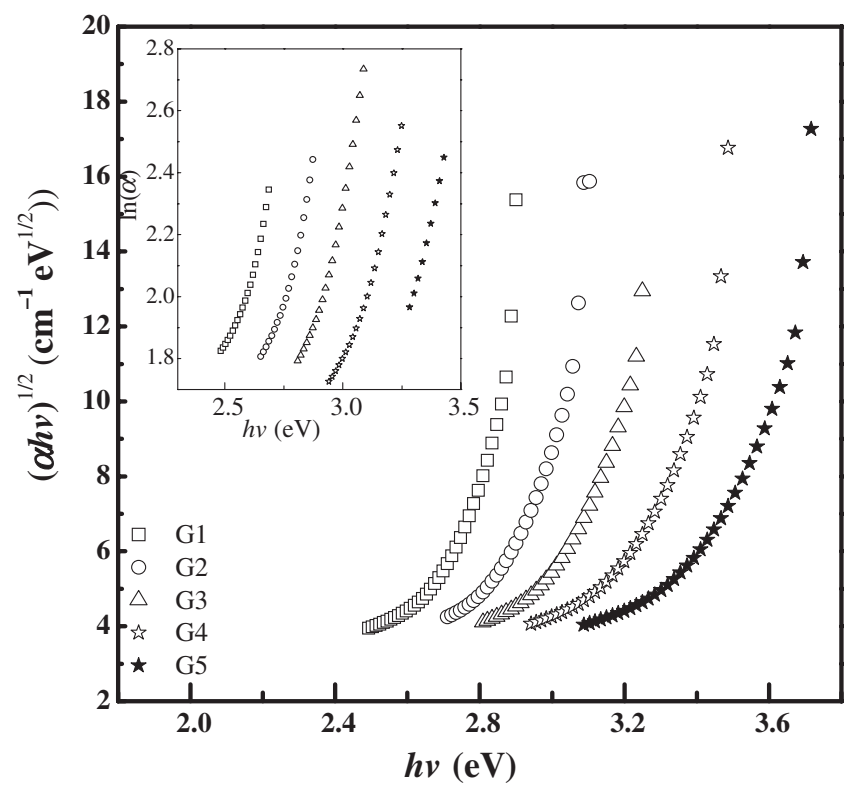

Figure 8. The plots of the absorption coefficient parameter $\sqrt{\alpha h \nu}$ as a function of $h v$ for G1-G5 glasses. The inset of this figure represents the absorption coefficient in logarithmic form $\ln (\alpha) v s$. $h v$ for G1-G5 glasses.

Table 5. The values of glass density, molar volume, optical parameters $\left(E_{\mathrm{e}}, E_{\mathrm{g}}, E_{0}, E_{\mathrm{d}}, n_{0}, \varepsilon_{\infty}\right)$, the electronic polarizability $\left(\alpha_{\mathrm{e}}(n)\right.$,

\begin{tabular}{|c|c|c|c|c|c|c|c|c|c|c|c|c|c|}
\hline \multirow[b]{2}{*}{ Glass } & $E_{\mathrm{e}}$ & $E_{\mathrm{g}}$ & $E_{0}$ & $E_{\mathrm{d}}$ & $n_{0}$ & \multirow[b]{2}{*}{$K\left(E_{\mathrm{g}}\right), \mathrm{GPa}$} & \multirow[b]{2}{*}{$\varepsilon_{\infty}$} & \multirow[b]{2}{*}{$E_{0} / E_{\mathrm{g}}$} & \multicolumn{3}{|c|}{$\alpha\left(\mathrm{A}^{3}\right)$} & \multirow{2}{*}{$\begin{array}{c}\chi^{(3)} \\
10^{13} \mathrm{esu}\end{array}$} & \multirow{2}{*}{$\begin{array}{c}n_{2}, \\
10^{12} \mathrm{esu}\end{array}$} \\
\hline & & & & & & & & & Eq. (4) & Eq. (5) & Eq. (6) & & \\
\hline G1 & 0.41 & 2.60 & 6.07 & 25.65 & 2.29 & 83.01 & 5.23 & 2.34 & 5.271 & 5.808 & 5.888 & 12.82 & 15.92 \\
\hline $\mathrm{G} 2$ & 0.36 & 2.75 & 6.27 & 25.37 & 2.25 & 85.12 & 5.05 & 2.28 & 5.311 & 5.834 & 5.952 & 10.78 & 12.96 \\
\hline G3 & 0.30 & 2.85 & 6.69 & 25.21 & 2.18 & 86.51 & 4.77 & 2.35 & 5.240 & 5.840 & 5.989 & 8.11 & 9.140 \\
\hline G4 & 0.27 & 3.05 & 7.01 & 24.58 & 2.12 & 89.26 & 4.50 & 2.30 & 5.288 & 5.884 & 6.112 & 6.07 & 6.52 \\
\hline G5 & 0.24 & 3.20 & 7.056 & 23.83 & 2.09 & 91.35 & 4.38 & 2.20 & 5.319 & 5.869 & 6.169 & 5.23 & 5.59 \\
\hline
\end{tabular}
$\left.\alpha_{\mathrm{e}}(K), \alpha_{\mathrm{e}}\left(E_{\mathrm{g}}\right)\right)$, the third-order non-linear susceptibility $\chi^{(3)}$ and the non-linear refractive index $n_{2}$ for phosphate rocks $-30($ limestone) $(70-x)$ borax $(0 \leq x \leq 40 \mathrm{wt} \%)$ glass system. 
where $\alpha_{0}$ is a constant and $\gamma$ is related to the width of the band tail of the localized state at the conduction or valence band edge [31]. When the $\alpha$-values in the logarithmic form are plotted against $h v$ as investigated in the inset of figure 8, the reciprocal of the slope gives the $\gamma$-value. The deduced values $\gamma$ and $E_{\mathrm{g}}$ are listed in table 5. The increase in $E_{\mathrm{g}}$ values with the increase of $\mathrm{CaO}$ content can be correlated to the decrease of the waste of the band into the gap $(\gamma)$. This decrease in the width of the band tail is ascribed to the decrease in the system disorder when $\mathrm{B}_{2} \mathrm{O}_{3}$ and $\mathrm{Na}_{2} \mathrm{O}$ molecules are replaced by $\mathrm{CaO}$ and $\mathrm{P}_{2} \mathrm{O}_{5}$ [27].

According to a previous work [34], a good correlation between the optical bandgap $\left(E_{\mathrm{g}}\right)$ and experimentally determined bulk modulus $(K)$ is presented in figure 9 . This correlation between the two parameters accordingly is given by

$$
K=46.89+13.89 E_{\mathrm{g}} \text {. }
$$

According to the theory of reflectivity of light, the refractive index $(n)$ values as a function of the reflectance $(R)$ and the extinction coefficient $(k)$ satisfy

$$
R=\frac{(1-n)^{2}+k^{2}}{(1+n)^{2}+k^{2}} .
$$

The $k$ values have been determined using the relation $(k=$ $\alpha \lambda / 4 \pi)$. Figure 10 shows the refractive index (RI) as a function of the wavelength from 300 to $2100 \mathrm{~nm}$, i.e., at energies ranging $4.1-0.59 \mathrm{eV}$ for the studied glasses. The listed values of RI in table 5 are obtained when $\lambda=\infty$, i.e., at zero energy. The high values of RI may be related to the existence of impurities from lime stones and phosphorite rocks, which act as scattering centers of UV. It was found that the values of RI decreases in the wavelength range of 300-21000 $\mathrm{nm}$ with the increase of the wavelength and the $\mathrm{CaO}$ content [35]. According to the Lorentz-Lorenz equation, the density of the material affects the refractive index in a direct proportion. Thus, the decrease in the values of the refractive index is ascribed to the decrease of the glass density that was

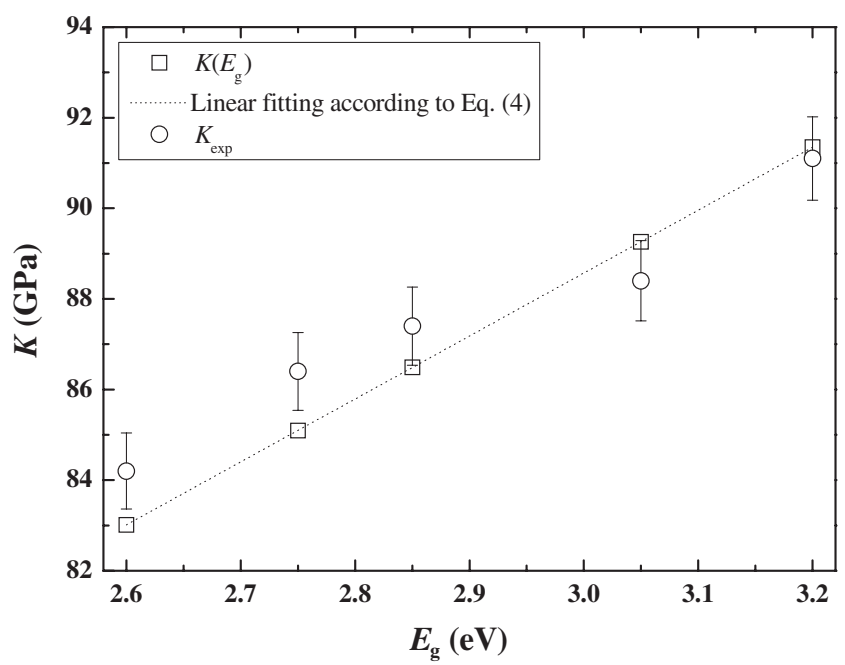

Figure 9. The bulk modules $(K)$ vs. optical bandgap $\left(E_{\mathrm{g}}\right)$ for G1-G5 glasses. attributed to the variation of the structural units as deduced from FTIR analysis.

The electronic polarizability $\left(\alpha_{\mathrm{e}}\right.$ in $\mathrm{A}^{3}$ ) can be determined from the known values of the optical parameters $n, K$ and $E_{\mathrm{g}}$ using the relationships [34,36]:

$$
\begin{aligned}
& \alpha_{\mathrm{e}}(n)=0.395\left(\frac{n^{2}-1}{n^{2}+2}\right)\left(\frac{M}{\rho}\right), \\
& \alpha_{\mathrm{e}}(K)=0.395\left(\frac{(5.563-0.033 K)^{2}-1}{(5.563-0.033)^{2}+2}\right)\left(\frac{M}{\rho}\right), \\
& \alpha_{\mathrm{e}}\left(E_{\mathrm{g}}\right)=0.395\left(\frac{12.41-\sqrt{E_{\mathrm{g}}-0.365}}{12.41+2 \sqrt{E_{\mathrm{g}}-0.365}}\right)\left(\frac{M}{\rho}\right),
\end{aligned}
$$

where $n$ is the refractive index value at $(h v=0 \mathrm{eV})$. The calculated values of $\alpha_{\mathrm{e}}(n), \alpha_{\mathrm{e}}(K)$ and $\alpha_{\mathrm{e}}\left(E_{\mathrm{g}}\right)$ are listed in table 5. From this table it is observed that, the $\alpha(n), \alpha(K)$ and $\alpha\left(E_{\mathrm{g}}\right)$ values are very close to each other. Thus, equation (4) was successfully able to calculate the $K$ values based on $E_{\mathrm{g}}$ values and vice versa. The difference between the experimentally determined bulk modulus $K$ values and that calculated by equation (4) is less than $1 \%$. Furthermore, any of the above equations (6-8) are suitable to calculate the electronic polarizability.

In the low-absorption region, the energy dependence of the refractive index obeys the Wemple and DiDomenico (WDD) oscillation model [30,37]:

$$
\left(n^{2}(h v)-1\right)^{-1}=\frac{E_{0}^{2}-h v^{2}}{E_{\mathrm{d}} E_{0}},
$$

where $E_{0}$ is the oscillator energy and $E_{\mathrm{d}}$ is the oscillator strength. Plotting a relation between $\left(n^{2}-1\right)^{-1}$ and $h v^{2}$ can give the values of $E_{0}$ and $E_{\mathrm{d}}$ as shown in figure 11 . As listed in table $5, E_{0}$ increases with the addition of $\mathrm{CaO}$ content as well as the $E_{\mathrm{g}}$ values or the observed blue-shift in the transmittance spectra. The oscillator energy $E_{0}$ is independent of the scale of the imaginary part of the dielectric constant $\left(\varepsilon_{2}\right)$ and consequently it can be considered as an average of the

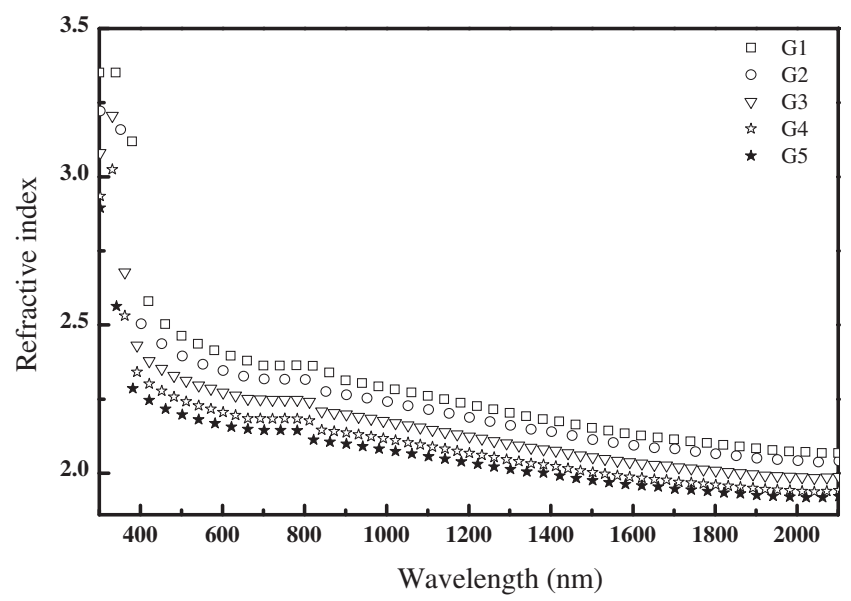

Figure 10. The refractive index $(n)$ as a function of the wavelength $(\lambda)$ for G1-G5 glasses. 


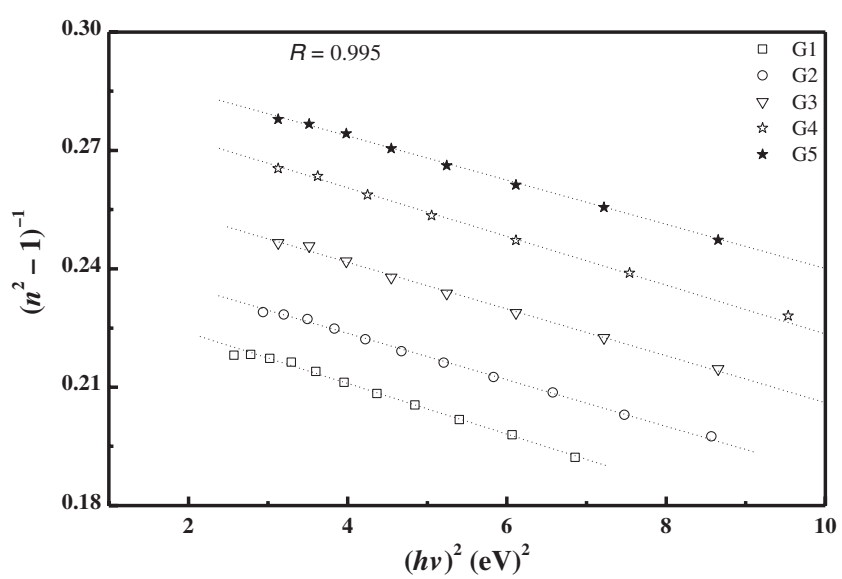

Figure 11. The plots of refractive index parameter $\left(n^{2}-1\right)^{-1} v s$. $h v$ for G1-G5 glasses.

energy gap $\left(E_{\mathrm{g}} \sim 0.5 E_{0}\right)$, whereas $E_{\mathrm{d}}$ depends on the scale of $\varepsilon_{2}$ and thus serves as an inter-band strength parameter [38].

The non-linear optical properties of the glasses under study can be discussed according to terms of Tichy and Ticha model [39]. According to these models, the third-order nonlinear susceptibility $\chi^{(3)}$ in esu units is given by Miller's generalized rule, $\chi^{(3)}=A\left(\chi^{(1)}\right)^{4}$, where $A=1.70 \times 10^{-10}$ and $\chi^{(1)}$ is the linear optical susceptibility that is based on the index of refraction as [40-42]:

$$
\chi^{(1)}=\left(n^{2}-1\right) / 4 \pi \text {. }
$$

Substituting $\chi^{(1)}$ into $\chi^{(3)}$ gives

$$
\chi^{(3)}=\frac{A\left(n^{2}-1\right)^{4}}{(4 \pi)^{4}} .
$$

Values of $\chi^{(3)}$ have been found to decrease with increasing $\mathrm{CaO}$ content (see table 5). Thus, the non-linear index of refraction can be determined through the following equation [40-42]:

$$
n_{2}=\frac{12 \pi \chi^{(3)}}{n} \text {. }
$$

The $n_{2}$ values decrease with increasing $\mathrm{CaO}$ content. This behaviour of $n_{2}$ can be correlated to the optical bandgap through the relation $n_{2} \propto\left(E_{\mathrm{g}}\right)^{-4}$ [43]. This relation shows that the results are consistent with the given relation. A similar behaviour for $n_{2}$ has been observed in other materials such as pure silica $\left(8.1 \times 10^{-14} \mathrm{esu}\right)$ and $\mathrm{As}_{2} \mathrm{~S}_{3}(3.51 \times$ $\left.10^{-11} \mathrm{esu}\right)$ at $800 \mathrm{~nm}[40,41]$. These results clearly indicated that the calculated values of $n_{2}$ for G1-G5 glasses are larger in comparison with that reported elsewhere [40-42].

\section{Conclusion}

Huge amounts of wastes are produced every year in the process of extraction of limestone and phosphorite from quarries of Egypt. Glass industry is one of the solutions of this problem, which is the aim of this study. As the content of phosphate rocks was increased in the glass batch, the concentrations of $\mathrm{CaO}$ and $\mathrm{P}_{2} \mathrm{O}_{5}$ increase and decrease the sodium diborate concentration while the concentration of $\mathrm{SiO}_{2}$ will be constant.

The pronounced effect of $\mathrm{CaO}$ on the FTIR bands of the network of borate-based glasses was observed in the range $40 \leq \mathrm{CaO} \leq 55 \mathrm{~mol} \%$. In this region, with respect to the variations in alkaline-earth content at the expense of alkaliboron, the investigated glasses exhibited depolymerization in glass network with increasing $\mathrm{Ca} /(\mathrm{Na}, \mathrm{B})$ ratio. As the $\mathrm{CaO}$ concentration increases, the concentration of the $\mathrm{CaO}_{6}$ structural unit increases, which transforms the $\mathrm{BO}_{4}$ tetrahedron into $\mathrm{BO}_{3}$ structural unit and $N_{4}$ decreases consequently. Beyond $55 \mathrm{~mol} \%$ of $\mathrm{CaO}$, the effect of the network glass former $\mathrm{P}_{2} \mathrm{O}_{5}$ was manifested in the appearance of new structural unit such as $\left[\mathrm{PO}_{2}^{-}\right]$. Thus, the vibrations of the bands related to vibrations of $\left[\mathrm{BO}_{3}\right]$ were shifted to lower wavenumbers, the vibrations of $\left[\mathrm{BO}_{4}\right]$ were shifted to higher wavenumbers and $\mathrm{N}_{4}$ seemed to be constant.

The increases of $\mathrm{CaO}$ and $\mathrm{P}_{2} \mathrm{O}_{5}$ decrease the concentration of the denser $\left[\mathrm{BO}_{4}\right]$ and so the density and the refractive index were decreased. The increases of the ultrasonic velocities, the elastic moduli and the optical bandgap were attributed to the increase of the concentration of the structural unit $\mathrm{CaO}_{6}$ which had high coordination number compared with the coordination of borate structural units. As a result, a polymerization of the total co-ordination number of the glass, crosslink density and connectivity within the glass network will occur. A good correlation between the computed bulk modulus from the optical bandgap $\left(E_{\mathrm{g}}\right)$ and the experimentally determined bulk modulus $(K)$ was found. The values of the electronic polarizability $\left(\alpha_{\mathrm{e}}\right.$ in $\left.\mathrm{A}^{3}\right)$ based on the optical parameters $n, K$ and $E_{\mathrm{g}}$ coincide with each other, i.e., the electronic polarizability can be calculated from any optical parameter.

\section{Acknowledgements}

We wish to thank Al-Azhar University-Egypt for the financial support.

\section{References}

[1] Saddeek Y B, Mohamed G Y, Shokry Hassan H, Mostafa A M A and Abd Elfadeel G 2015 J. Non-Cryst. Solids 419110

[2] Saddeek Y, Shokry Hassan H and Abd Elfadeel G 2014 J. Non-Cryst. Solids $\mathbf{4 0 3} 47$

[3] Scarinci G, Brusatin G, Barbieri L, Corradi A, Lancellotti I, Colombo P, Hreglich S and Dall'Igna R 2000 J. Eur. Ceram. Soc. 202485

[4] Hentati O, Abrantes N, Caetano A L, Bouguerra S, Gonçalves F, Römbke J and Pereira R 2015 J. Hazardous Mater. 29480

[5] Singh S, Kumar A, Singh D, Thind K S and Mudahar G S 2008 Nucl. Instrum. Methods Phys. Res. Sec. B: Beam Int. Mater. Atoms 266140 
[6] Cetin S, Marangoni M and Bernardo E 2015 Ceram. Inter. 41 5294

[7] Chinnam R K, Francis A A, Will J, Bernardo E and Boccaccini A R 2013 J. Non-Cryst. Solids 36563

[8] Khater G A and Morsi M M 2011 Thermochim. Acta 5196

[9] Colombo P, Brusatin G, Bernardo E and Scarinci G 2003 Curr. Opin. Solid State Mater. Sci. 7225

[10] Maheshwaran et al 2014 Appl. Phys. A 1171323

[11] Doweidar H, El-Damrawi G and Al-Zaibani M 2013 Vibr. Spectrosc. 6891

[12] Mandlule A, Döhler F, Van Wüllen L, Kasuga T and Brauer D S 2014 J. Non-Cryst. Solids 39231

[13] Ren M, Cai S, Zhang W, Liu T, Wu X, Xu P and Wang D 2013 J. Non-Cryst. Solids $\mathbf{3 8 0} 78$

[14] Saddeek Y B, Azooz M A and Kenawy S H 2005 Mater. Chem. Phys. 94213

[15] Doweidar H and Saddeek Y B 2009 J. Non-Cryst. Solids 355 348

[16] Aronne A, Depero L E, Sigaev V N, Pernice P, Bontempi E, Akimova O V and Fanelli E 2003 J. Non-Cryst. Solids 324 208

[17] Pascuta P, Lungu R and Ardelean I 2010 J. Mater. Sci.: Mater. Electron. 21548

[18] Doweidar H, El-Damrawi G and Abdelghany M $2012 \mathrm{~J}$. Mater. Sci. 474028

[19] Baccaro S, Monika G, Sharma K S, Thind D and Singh A C 2007 Nucl. Instrum. Methods Phys. Res. Sec. B: Beam Int. Mater. Atoms 260613

[20] Tulyaganov D U, Agathopoulos S, Fernandes H R and Ferreira J M F 2006 J. Eur. Ceram. Soc. 261131

[21] Doweidar H and Saddeek Y B 2010 J. Non-Cryst. Solids 356 1452

[22] Goel A, McCloy J S, Fox K M, Leslie C J, Riley B J, Rodriguez C P and Schweiger M J 2012 J. Non-Cryst. Solids 358674
[23] Vincent V, Nihoul G and Gavarri J R 1996 Solid State Ion. 9211

[24] Mansour E 2012 J. Non-Cryst. Solids 358454

[25] Saddeek Y B, Gaafar M S and Bashier S A 2010 J. Non-Cryst. Solids 3561089

[26] Saddeek Y B, Afifi H A and Abd El-Aal N S 2007 Physica B Condens. Matter 3981

[27] Saddeek Y B, Aly K A and Bashier S A 2010 Physica B Condens. Matter 4052407

[28] Luo Z W, Lu A X, Chen B, Zhou J L and Ren F 2011 Physica B Condens. Matter 4064558

[29] Matori K A, Zaid M H M, Aziz S H A, Kamari H M and Wahab Z A 2013 J. Non-Cryst. Solids 36178

[30] Aly K A 2010 Appl. Phys. A 99913

[31] Aly K A 2009 J. Non-Cryst. Solids 3551489

[32] Aly K A, Abousehly A M, Osman M A and Othman A A 2008 Physica B Condens. Matter $\mathbf{4 0 3} 1848$

[33] Tauc J 1967 Science 1581543

[34] Aly K A 2015 J. Alloys Compd. 630178

[35] Moustafa E S, Saddeek Y B and Shaaban E R 2008 J. Phys. Chem. Solids 692281

[36] Aly K A 2015 J. Alloys Compd. 630178

[37] Wemple S H and Didomenico M 1969 Phys. Rev. Lett. 23 1156

[38] Sharma P, Dahshan A and Aly K A 2014 J. Alloys Compd. 616323

[39] Tichá H and Tichý L 2002 J. Optoelectron. Adv. Mater. 4381

[40] Smolorz S, Wise F and Borrelli N F 1999 Opt. Lett. 241103

[41] Asobe M, Kanamori T and Kubodera K I 1993 IEEE J. Quant. Electron. 292325

[42] Sharda S, Sharma N, Sharma P and Sharma V 2013 J. Electron. Mater. 423367

[43] Moss T S 1985 Phys. Status Solidi (B) Bas. Res. 131415 